DOI 10.37882/2500-3682.2021.12.28

\title{
ПРОБЛЕМА СВОБОДЫ ВОЛИ В ОТЕЧЕСТВЕННОЙ ФИЛОСОФИИ
}

\section{THE PROBLEM OF FREEDOM OF WILL IN DOMESTIC PHILOSOPHY}

S. Chugunov

Summary: The article is devoted to the consideration of the problem of free will in Russian philosophy. Special attention in the process of research is paid to the study of the semantic content of the concept of «will» in the historical and paradigmatic retrospective. The ways and methods of strengthening and enriching faith are also indicated. More close attention in the article is paid to the key conditions and concepts that a person needs for his own self-realization. Particular emphasis is placed on the obstacles for a person to achieve freedom and ways to overcome them.

Keywords: God, man, freedom, will, responsibility.

\author{
Чугунов Сергей Владимирович \\ к.филос.н., доцент, ФГАОУ ВО «Севастопольский \\ Государственный университет» \\ serzh.chugunov.62@mail.ru
}

Аннотация: Статья посвящена рассмотрению проблемы свободы воли в отечественной философии. Отдельное внимание в процессе исследования уделено изучению смыслового содержания понятия «воля» в исторической и парадигмальной ретроспективе. Также обозначены способы и методы укрепления и обогащения веры. Более пристальное внимание в статье уделено ключевым условиям и концептам, которые необходимы человеку для собственного самоосуществления. Особый акцент сделан на препятствиях для достижения человеком свободы и способах их преодоления.

Ключевые слова: Бог, человек, свобода, воля, ответственность.
$\mathrm{B}$ опрос о свободе воли является одной из центральных проблем в религиозной философии, в том числе, и в отечественной философской мысли. Решение этой проблемы требует от философов ответа, по крайней мере, на три основных вопроса. Во-первых, как соотносятся необходимость и свобода, то есть, является ли действие человека, действительно свободным? Во-вторых, какова степень ответственности человека за индивидуальные действия и поведение? В-третьих, если личность совершает своевольное действие, то какое следует наказание за него.

Неоднозначность смыслового содержания понятия «воля» привели к возникновению позиций, отрицающих свободу воли, как реальный процесс. Например, Сеченов И.М. утверждал, что воля, как психический процесс зависит от множества факторов, как внутренних, так и внешних. В связи с этим, применять понятие свобода к волевым процессам нельзя. П.Л. Лавров считал, что действия человека определяются долгом, как основой нравственного поведения, поэтому, нет и не может быть свободы в проявлении воли.

Воля - это действительная сущность человека, отмечал А.С. Хомяков. По его мнению, она не всегда, доступна рассудочной деятельности и сознательному анализу, занимая особое место в человеческом духе. Понимание воли, как указывал философ, не дается человеку из окружающего его мира. Функция воли заключается в возможности устанавливать различие между действительным предметом и его фантастическим представлением или образом, то есть, как утверждал философ, между тем, что исходит от человека и тем, что ему не принадлежит. Она не порождается никаким миром явлений и не может в него перейти. Личность не в состоянии перенять волю из чужого опыта, так как опытным путем она не передается. Человек никогда не встретит вольный предмет, не увидит его, ибо ни один предмет вольным действием не обладает. Отсутствие воли или болезненное состояние препятствует процессу мышления, так как личность не может различить реальный предмет, от воображаемого образа. Воля, как указывал философ, способствует формированию понятий, раскрывая их источник и ограничивая пределы действий личности.

Существование воли, как силы, не вызывает сомнения, считал Хомяков. Но, в тоже время, как силы свободной, ее проявления не так являются характерными и определенными. Философ писал: «Мнимое и на словах высказываемое сомнение объясняется, во-первых, тем, что свободная воля, как до - предметная сила мысли, никогда не может перейти в предмет, познаваемый диалектическим рассудком; во-вторых потому, что она в человеке не полна и не совершенна, как сам разум, и что частное (человек) стремится волить, как оно стремится разуметь; ибо оно само есть только стремление, а не бытие в смысле сущего.» [1, с.201].

Русский философ не отрицал возможность возражения по отношению к его позиции. По его мнению, противоположный аргумент сводится к следующим положениям. Человек - это центр всех сил, которые осознаются им как внешние и как необходимость, имеющие самостоятельное значение. Сознание признает влияние этих сил и реакцию на них как отдельную от воли. На самом деле, как считал философ - это не так. Воздействие внешних сил не может быть самодеятельным. Оно всегда имеет причину, но индивидуальный разум не всегда ее может установить. Поэтому, воля, пусть и минимально, участвует в любом процессе, который, осознается чело- 
веком и требует от него принятия решения и обратного действия.

Человеку свойственно осознавать или чувствовать свои физические пределы и недостатки, но не в границах воли, а в результате впечатлений. Эти впечатления, как утверждал Хомяков, носят двойственный характер, так как связаны с деятельностью различных органов чувств. Поэтому, опираясь на свои внутренние впечатления, человек не всегда их связывает с действием воли. Например, судорогу, мигание, по мнению философа, люди не относят к волевым процессам. Воля - это основа творческой активности разума и возможности логически отражать внешний мир рассудком.

Условием укрепления и «обогащения» воли является вера. Вера - это внутреннее, истинное знание. Оно не доступно тем людям, которые, по мнению философа, отреклись от душевной любви и лишили себя божественной благодати, поэтому им доступно, только «внешнее знание». «Внешнее знание» не раскрывает смысл бытия, не способствует достижению духовных тайн. Вера сдерживает личные страсти, воспитывая терпение. Она требует уважения и искренности. Ее нельзя использовать, как средство устрашения или защиты.

Человек ничтожен и мал, по сравнению с другими божественными творениями, например, с тем, что изучает астрономия. В тоже время, как утверждал русский философ, человек - это венец творения. Он является смыслом того, что сотворено Богом, поэтому воплощает в себе свою завершенность. Только человеческая личность способна реализовать тот божественный замысел, который вложил создатель в мироздание. Задача человека заключается в сохранении и спасении мира, путем внесения в него силы любви и гармонии.

Для собственного самоосуществления, любой человек имеет два направления: мир индивидуальный и единый соборный мир. В первом мире человек не развивается полноценно, осознает свою ограниченность, и не всегда может удержать себя в границах духовного согласия. Противостоящий мир предметов и физических сил влияют на жизнь людей и «заставляют» их проявлять активность. Но в этой активности проявления воли нет.

В мире соборном, человек чувствует себя индивидуальностью, которая свободно находит себя в единстве любви. Хомяков убежден, что свобода не проявляется как стихийная сила, а является неотъемлемым качеством личности, получившим в христианстве высокое развитие через истинное понимание смысла свободного действия. Личность в христианстве возвышена над земным миром и нравственно, бесконечно развивается по закону любви. «Лишь в Церкви, т.е. в свободном, проникнутом братской любовью к другим людям единении во имя Христа, - только здесь личность обретает все свои дары, всю полноту своего личного богатства. Разум, совесть, художественное творчество вне Церкви реализуют себя всегда частично и неполно» - писал В.В. Зеньковский, оценивая идеи Хомякова [2, с.185].

Проблема свободы в философии всеединства - это, прежде всего, процесс свободного самоосуществления человека перед лицом Бога. Как неотъемлемый элемент всеединства, человек сам себя определяет, сам себя утверждает. Но, в этом случае, он подлежит миру необходимости, а необходимость является одним из состояний существования, в которых может пребывать личность. Человек выше своих состояний, ведь, свободное существование по законам собственного бытия, позволяет ему, в конечном итоге, быть независимым от Божественного откровения. Осуждая себя и свои действия, человек в отличие от других земных существ относится к себе критически, подвергая оценке сам способ своего существо Разум, как считал Соловьев, указывает человеку о факте его возможного несовершенства. Совесть, как внутренний голос говорит ему, что этот факт не является только внешней необходимостью, а зависит от него самого, от его активной воли. Человек - это связь условного и безусловного, ничтожного и божественного.

Ф.М. Достоевский признавал свободу и зло равноправными. Соловьев не согласился с этим утверждением, полагая, что свобода не всегда сопровождается злым началом. Злом нельзя назвать, свободное стремление каждого существа к независимости. Злым не может быть и желание обрести единство с миром, стать частью всего. Правда, как подчеркивал философ, это желание, является правильной целью нашей свободы. Только в условиях сотворенного мира, разделенного на отдельные элементы, эта цель реализуется через подчинение этих элементов мира себе, а это уже является злом. Отечественный философ, таким образом, сделал вывод, что, зло связано с «неправильной» реализацией нашей свободы, и причина этой «неправильности» заключается в жестком разделении друг от друга существ, обладающих свободой.

Соловьев указывал, что для объективного подхода к решению проблемы свободы воли, необходимо дать научное определение понятия воли. Анализируя различные степени проявления воли, отечественный философ пришел к выводу, что воля, как акт решения характерна для существ, обладающих способностью отвлечённого мышления. Философ объяснял, человек может иметь множество желаний, стремлений, поэтому ему предстоит выбор между ними. Этот выбор свободен, так как он определяется не актом желания, а известным принципом или идеей. Но этот выбор не свободен, если под свободой понимать отсутствие мотива, как причины или способность решится на какое - то действие без должного основания. 
Все подходы к решению проблемы свободы воли, философ разделил на две большие группы: не философские и философские. К первой группе русский философ отнес распространенные среди людей, представления о свободе действий и возможного наказания за него.

Так, одно из представлений, например, было названо криминальным подходом. Соловьев отмечал: «Если свободы воли нет, говорят представители этой точки зрения, то нет и вменяемости: если человек действует не по свободному выбору, а по безусловной необходимости, то он не может быть виновен в тех или других своих действиях, так как он не мог не совершить этих действий» $[2$, с.130].

Истоки философского решения проблемы свободы воли, по мнению русского философа, можно найти уже в античности и носят нравственно - психологический характер. Для Сократа путь к разумной свободе сводился к процессу поиска знания добра. Аристотель утверждал, что для разумного выбора необходима воля. Благодаря воле человек, отличает предметы и имеет возможность совершать нравственные действия, не нарушая гармонии.

Для философии христианства, воля - это естественное качество человека, приближающее его к Богу. Человек обладает свободой выбора, он имеет множество способов достичь поставленной цели. Соловьев пришел к выводу, что для христианства свобода воли заключается в поиске решения и ответственности за него.

Характерной чертой философского подхода в период Нового времени, русский философ считал поиск ответа на вопрос о соотношении между свободой и необходимостью. Не занимая определенной позиции, философ указывал, что свободу можно определить, как один из видов необходимости. Если под свободой понимать процесс или желание подчинить личные стремлении, каким-либо высшим мотивам, то человек, действительно, свободен. Но, как подчеркивал Соловьев, эта свобода человека вообще. Если говорить о конкретной личности, то можно ли утверждать, что любое индивидуальное действие согласуется с нравственными нормами, а не противоречит им. Но, чаще всего человек не следует по этому пути, поэтому, сделал вывод русский философ, вопрос о свободе воли не может иметь однозначного решения.

Н.А. Бердяев подверг критике подход, определяющий свободу воли как процесс необходимого выбора между добром и злом. По его мнению, такая позиция, скорее свидетельствует о порабощении человека, чем о процессе его освобождения. Философ объяснял, что человек вынужден выбирать то, что ему навязано, и следовать нормам под страхом ответственности. Но, индивидуальная свобода может проявляться не только в действиях, ведущих к общему благу или следованию нравственным нормам, вытекающих из свободной воли. Свобода может проявляться как активная творческая деятельность, как создание духовных или материальных ценностей. Свобода воли как свобода выбора ограничивает потенциальные возможности личности и не ведет к истинному освобождению. Наоборот, личность может почувствовать себя освобожденной, когда ей не надо выбирать, и оказаться в двойственной ситуации, когда выбор уже сделан. Философ подчеркивал, что такой подход к решению проблемы свободы воли, унижает человека, лишает его творческой активности и представляет сложный процесс личного становления, как стремление что-либо принять или отвергнуть. Человек, по-настоящему, свободен, когда ему не надо выбирать.

В человеке, как утверждал Бердяев, могут сосуществовать два порыва, один ведет его к свободе, второй к рабству. Господин и раб, как две структуры осознания своей жизни уживаются в человеке и не существуют друг без друга. Человек может проявить слабость, отказаться от свободы, ради спокойствия. Свободный не только существует сам по себе, но и не нуждается в какой-либо противоположности. Чтобы быть свободным, человек обязан изменить свою жизнь, установки и мотивы своей деятельности, признать новые ценности. Свободная личность отказывается от власти социальных мифов, отвергает их. Для нее не существуют универсальные законы и нормы, которым надо подчиняться. Философ писал: «Свобода есть внутренняя энергия человека. Через свободу человек может творить новую жизнь, новую жизнь общества и мира» [3, с.325].

Свобода иррациональна, она предшествует бытию, поэтому не должна рассматриваться как условие построения и достижения совершенного социального строя. Свобода не может быть правом, гарантии которого предоставляет общество или зависят от него. Русский философ подчеркивал, что свобода - это тяжелая обязанность. Обязанность заключается в том, что человек, добровольно, принимает перед Богом долг быть свободным человеком, а не рабом. Поэтому составляющей частью свободы является сопротивление, как форма проявления силы воли. Проявляя силу воли, человек противостоит внешним для него воздействиям, и познает границы своей свободы. Для того, чтобы человек проявлял желание бороться, по мнению философа, необходимо наличие уверенности в реальности личной свободы, а не чувство, так как оно может быть иллюзорным.

Свобода противоречива. Люди, стремясь сохранить какие-либо социальные ценности воспринимают свободу, как неподвижность и неизменность, а ее движение и рост как отрицание свободы. Статичность губительна для свободы, так как рождает стремление к разрушению основ творческой активности людей. 
Бердяев выделял различные ступени социальной свободы. Увеличивается свобода по мере приближения к духу, а уменьшается, приближаясь к материи. Любая попытка возвысить материальную сторону жизни, ведет, к позиции превосходства материального богатства над духовными ценностями. Материальная свобода заключается в постоянном стремлении к обладанию чем - либо, но владеть еще не означает быть свободным. Богатство не освобождает личность, а, наоборот, подавляет ее. Поэтому, как утверждал русский философ, экономическая свобода должна быть ограничена, иначе она станет условием эксплуатации народа.

Свобода - это процесс духовного подъема. Этот процесс не заключается в отходе от реальности, а, наоборот, предполагает взаимодействие с ней, с целью освобождения от всего враждебного. Духовное освобождение заключается в саморазвитии личности, преодоления страха в себе, путем поиска истины. Философ подчеркивал, что познание истины ведет к познанию смысла свободы. А истиной, по мнению Бердяева, является любовь к Богу. Вера способствует пониманию человеком своих недостатков. Любовь ведет к желанию борьбы с ними, так как пороки мешают осознанию, что любовь - это не только счастье, но и сострадание, соучастие в жизни другого человека, единство с ним. Вера не принуждает человека, она не терпит влияния авторитета, поэтому, она всегда содержит в себе свободное действие. Вера всегда содержательна и конкретна, отрицает любой формализм, в том числе, и в вопросе религиозной свободы.

Самоопределяясь, человек расширяет границы своего внутреннего мира. Человек в своей индивидуально-неповторимой жизни может рассматриваться как носитель божественного начала, Абсолют, определяющий все, что существует в действительности. Только при полном развитии сил свободы, человек, а благодаря его внутренней активности, весь мир, смогут достичь идеального состояния, который уже невозможно будет уничтожить.

Л. Шестов считал проблему свободы воли одним, из самых сложных вопросов, как в философии, так и в теологии. По его мнению, для решения этой проблемы необходимо, либо искажать действительность, либо прибегать к парадоксальным противоречиям, либо, как Платон, использовать мифы. Используя различные примеры, в том числе и исторического характера, философ сделал вывод, что действия людей являются проявлением индивидуальной, свободной жизни. Перед личностью всегда стоит вопрос: могу ли я поступить иначе или должен поступать определенным образом? Поэтому, как отмечал философ, проблема свободы воли подвергалась пересмотру в те исторические периоды, когда вставал вопрос об истоках и условиях бытия. Человек - это образ и подобие Бога, он имеет право, как творческая индивидуальность, вступать в спор с Богом, проявляя стремление к самоосуществлению. В подходе к отношению к Богу, философ видел основу решения проблемы свободы воли.

С целью, более подробного анализа подходов к решению проблемы свободы воли, Шестов дал краткую характеристику ряду концепций. Первую концепцию, условно, можно назвать «традиционной», так как, по мнению философа, она имеет глубокие исторические корни. В ее основе лежит утверждение, что свобода воли - это действия для выполнения, которых у человека есть все «основания». Свобода, в этом случае, рассматривается как процесс, разложенный на бесконечное количество бесконечно малых элементов. Но, какими должны быть эти «основания»? Вспоминая притчу о Буридановом осле, отечественный философ, воспользовался примером. Представим ситуацию, что перед очень голодным человеком лежат два куска хлеба. Какие есть «основания» у него, чтобы выбрать один кусок и отвергнуть второй, при этом не остаться голодным. Характерная особенность данной позиции - признание индивидуального, особенного чем-то не реальным или не заслуживающим внимания. Даже простые действия, считал Шестов, могут не зависеть от желания что-либо предпринять. Жизнь людей полна неожиданностями, даже, при одних и тех же условиях, один человек может поступать свободно, а другой нет.

Концепции, отрицающие свободу воли, Шестов, рассмотрел более подробно. Их основу составляет положение: свободная воля у Бога и только у Бога. Он писал: «Было бы безумием предоставить человеку «свободно» принимать какие бы то ни было решения. Бог дал уже однажды свободу первому человеку - и увидел, что все лучше, чем такое положение: человек променял рай на нашу жалкую, земную жизнь!» [4, с. 207]. Философ объяснял, что утрата свободы человеком предопределена историей развития человечества. Утратив связь с божественным миром, люди поверили, что свобода заключается в возможности выбора между добром и злом. Но, в божественном мире нет зла, поэтому и не может быть выбора, так как выбирать не было необходимости. Свобода заключается во власти над злом, в стремлении не допустить его в мир людей.

Более близкой к собственным взглядам, Шестов считал позицию М. Лютера. По его мнению, Лютер, отрицая какие-либо философские или религиозные традиции, несколько иначе ставил вопрос о свободе воли. Так, большинство философов утверждали, что человек, либо свободен, либо нет, а если нет, то его действия включены в непрерывную цепь явлений, определяемую совокупностью причин. Лютер допустил свободу воли человека в мире явлений. Люди свободно могут решать проблемы, связанные с их обыденной жизнью, 
принимать решения по различным вопросам. Отечественный философ пришел к выводу, что для Лютера, закономерности мира не являются препятствием для свободы человека. Наоборот, люди свободно действуют в закономерном мире, так как могут не знать механизмы и принципы его строения. Но из того, что человек свободен во многих отношениях, для Лютера не следовало, что его можно считать абсолютно свободным существом.

Шестов утверждал, что возможности жизни ограни- чены, трудно все понять или ответить на все вопросы. Слабость человеческой воли заключается в том, что люди не хотят действовать. Человек, часто к чему-либо стремится, но достигнуть приемлемого результата не может. В этом случае, как утверждал отечественный философ, энергия воли и страсти направляется не на созидание, а на поддержание внутренних сил. Внутренняя работа разрушает дух человека и является причиной ослабления его воли. Люди не только перестают бороться, но, даже, не могут противостоять внешним условиям своей жизни.

\section{ЛИТЕРАТУРА}

1. Хомяков А.С. Избранные философские произведения. / А.С. Хомяков - Харьков: АСТ, $1996-458$ с.

2. Соловьев В.С. Избранные статьи и письма / В.С. Соловьев. - М.: ЭКСМ0, 2001. - 654 с.

3. Бердяев Н.А. Царство духа и царство кесаря. / Н.А. Бердяев - М.: Республика, 1995. - 383 с.

4. Шестов Л. Сочинения в 2- х томах. / Л. Шестов. - М.: Наука. - 1993. - Т. 2- 557 с.

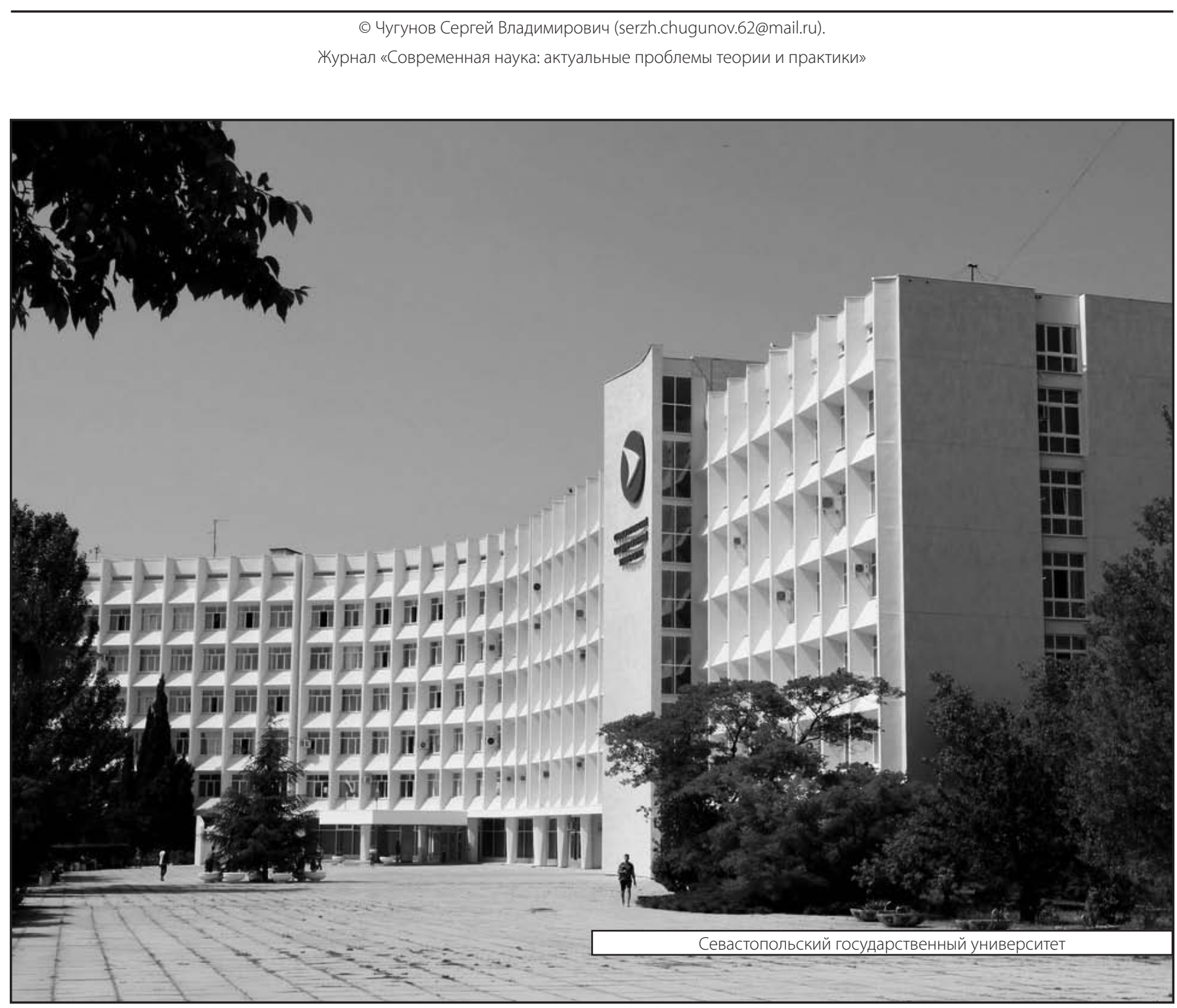

